\title{
Effect of exercise on serum creatine kinase in carriers of Duchenne muscular dystrophy
}

\author{
RONALD F GAINES, SIEGFRIED M PUESCHEL, EDWARD A SASSAMAN, \\ AND JAMES L DRISCOLL
}

\begin{abstract}
From the Child Development Center, Department of Pediatrics, Rhode Island Hospital, Brown University-Program in Medicine, Providence, Rhode Island, USA
\end{abstract}

SUMMARY In order to evaluate the effect of exercise on serum creatine kinase levels, blood samples were obtained from 17 normal females and 12 Duchenne muscular dystrophy carriers before and 9 hours after moderately strenuous exercise. The results revealed that after exercise serum creatine kinase levels may be better indicators of carrier status than resting levels. The mean serum creatine kinase levels before and after exercise, as well as the mean increases, were found to be significantly greater in Duchenne muscular dystrophy carriers than in normal control subjects.

Numerous studies have been concerned with the identification of carriers of Duchenne muscular dystrophy. Past investigators have focused on the rise in serum enzymes, ${ }^{1-3}$ abnormal muscle ultrastructure, ${ }^{4}$ myopathic changes of the electromyogram, ${ }^{5}$ derangement in muscle protein synthesis, ${ }^{6}$ and muscle weakness. ${ }^{7}$ Other studies reported aberrations in the electrocardiogram, ${ }^{8}$ red blood cell morphology, ${ }^{9}$ membrane protein peak II phosphorylation activity, ${ }^{10} 11$ and lymphocyte capping, ${ }^{12}$ in carriers of this $\mathrm{X}$ linked neuromuscular disorder. Unfortunately, many of these pathological findings are not observed in all carriers of Duchenne muscular dystrophy, some of the tests are cumbersome or invasive in nature, and other studies which have not been duplicated await confirmation.

At present, serum creatine kinase determination is the most widely used method for carrier detection $^{13} 14$ though it has been proposed that pyruvate kinase may be a more sensitive indicator. ${ }^{2}$ Since there is considerable variation in serum creatine kinase levels among known carriers, several enzyme determinations are usually made in the attempt to establish carrier status. ${ }^{15}$ During the days before testing, undue motor activity is usually avoided ${ }^{13}$ because it has been shown that moderately heavy exercise will result in increased serum creatine kinase levels. ${ }^{16-19}$

This study was directed towards the evaluation of the hypothesis that the serum creatine kinase concentration several hours after a measured exercise would constitute a more effective carrier detection method.

Received for publication 3 March 1981

\section{Subjects and methods}

Seventeen healthy female volunteers, between the ages of 20 and 41 , who did not have clinical muscle weakness, participated in this study as controls. Obligate, probable, and possible carriers known to us through contacts with Duchenne muscular dystrophy patients followed at the Child Development Center were invited to take part in this investigation. Both control and study populations were asked to refrain from unusual exercise for 2 days before testing. The study design, rationale, and test procedure were explained and the subjects gave written informed consent.

On the morning of the test, the participants weight was recorded, a venous blood sample was drawn, and the subjects were asked to pedal a Schwinn EX-1 Bicycle Ergometer to produce 5000 to 6000 kilopond-metres of work within a 10 to 12 minute period. The exercise load setting, which was 900 kilopond-metres/minute at the beginning was reduced to 600 and later to 450 kilopond-metres/ minute when the subjects became exhausted at the initial higher exercise levels. After completion of the exercise, the participants were permitted to go about their usual daily activities with restriction only of undue exercise. Based on the evaluation of previous reports, ${ }^{16-20}$ we obtained a second venous blood sample, approximately 9 hours after completion of the exercise.

All blood specimens were centrifuged and the serum was frozen. Serum creatine kinase determinations were carried out within 48 hours at $37^{\circ} \mathrm{C}$, according to the method of Szasz et al..$^{22}$ 


\section{Results}

Table 1 presents the age, weight, total exercise load, and serum creatine kinase activity immediately before and 9 hours after exercise of 17 normal appearing control females. Equivalent data for female relatives of patients with Duchenne muscular dystrophy are shown in table 2 . In genetic terms, these include definite, probable, and possible carriers. However, based on pedigree evaluations and previous significantly increased serum creatine kinase levels, it is assumed that the subjects listed in table 2 are Duchenne muscular dystrophy carriers. Table 3 contrasts the mean serum creatine kinase levels before and 9 hours after exercise as well as the mean increases of serum creatine kinase between the controls and carriers. These data indicate that the after exercise values may be more discriminating than both the before exercise levels and the net change between the first and second blood samples.

A graphic presentation of a discriminant function
TABLE 3 Comparison between serum creatine kinase (CK) levels of controls and carriers

\begin{tabular}{lcll}
\hline & $\begin{array}{l}C K(I U) \\
\text { before exercise } \\
(\text { mean } \pm 1 S D)\end{array}$ & $\begin{array}{l}\text { CK }(I U) \\
\text { after exercise } \\
(\text { mean } \pm 1 S D)\end{array}$ & $\begin{array}{l}\text { Delta } C K \\
(I U) \\
(\text { mean } \pm 1 S D)\end{array}$ \\
\hline Controls & $56 \pm 19$ & $68 \pm 26$ & $12 \pm 19$ \\
Carriers & $373 \pm 394$ & $532 \pm 505$ & $159 \pm 161$ \\
p value & $<0.025$ & $<0.015$ & $<0.02$ \\
\hline
\end{tabular}

analysis is depicted in the figure. A log log transformation was used because of the extreme skewness of the distributions. The $\mathrm{X}$ near the centre of the graph indicates a mid-point between the means of the two groups. The classification boundary is shown by the broken line, which is the boundary that would be expected to produce the minimum misclassification. Since the calculated boundary is more horizontal than vertical, it implies that the after exercise value is more important than the before exercise value in making the discrimination.

TABLE 1 Age, weight, total exercise load, and serum creatine kinase $(C K)$ determinations in normal appearing control subjects,

\begin{tabular}{|c|c|c|c|c|c|c|}
\hline Subject & Age $(y r)$ & Weight $(k g)$ & Exercise (kpm) & $\begin{array}{l}C K(I U) \\
\text { before exercise }\end{array}$ & $\begin{array}{l}C K(I U) \\
\text { after exercise }\end{array}$ & $\begin{array}{l}\text { CK }(I U) \\
\text { change }\end{array}$ \\
\hline 1 & 37 & $56 \cdot 4$ & 5775 & 42 & 42 & $\mathbf{0}$ \\
\hline 3 & 27 & 53 & 6000 & 58 & 47 & -9 \\
\hline 4 & 22 & 50 & 6750 & 39 & 42 & +13 \\
\hline 5 & 26 & 49 & 5350 & 40 & 103 & +63 \\
\hline 6 & 26 & $49 \cdot 5$ & 6675 & 55 & 44 & -9 \\
\hline 8 & 38 & $76 \cdot 5$ & 6100 & 78 & 92 & +14 \\
\hline 9 & 26 & 63 & 6490 & 44 & 49 & +5 \\
\hline 10 & 32 & 56 & 6750 & 68 & 80 & +12 \\
\hline 11 & 36 & $63 \cdot 3$ & 5624 & 55 & 108 & +53 \\
\hline 12 & 31 & $53 \cdot 3$ & 6750 & 52 & 65 & +13 \\
\hline 13 & 30 & 70 & 4565 & 77 & 73 & -4 \\
\hline 14 & 34 & $72 \cdot 6$ & 7200 & 62 & 73 & +11 \\
\hline 15 & 41 & $62 \cdot 8$ & 5300 & 25 & 20 & -5 \\
\hline 16 & 20 & 47 & 6700 & 105 & 113 & +8 \\
\hline
\end{tabular}

TABLE 2 Age, weight, total exercise load, and serum creatine kinase $(C K)$ determinations in female relatives of patients with Duchenne muscular dystrophy

\begin{tabular}{|c|c|c|c|c|c|c|c|}
\hline Subject* & Affected relatives & Age $(y r)$ & Weight $(k g)$ & Exercise (kpm) & $\begin{array}{l}C K(I U) \\
\text { before exercise }\end{array}$ & $\begin{array}{l}C K(I U) \\
\text { after exercise }\end{array}$ & $\begin{array}{l}\text { Increase of } \\
C K(I U)\end{array}$ \\
\hline 1 & 2 sons & 34 & 52 & 5550 & 175 & 365 & +190 \\
\hline 2 & 2 sons & 50 & 51 & 3787 & 164 & 188 & +24 \\
\hline 3 & 3 sons & 42 & 65 & 6975 & 52 & 88 & +36 \\
\hline 4 & 3 brothers, 1 son & 32 & 55 & 5700 & 178 & 320 & +142 \\
\hline 5 & 2 sons & 43 & 67 & 5475 & 106 & 148 & +42 \\
\hline 6 & 1 uncle, 1 son & 45 & 80 & 5075 & 160 & 207 & +47 \\
\hline 8 & 2 brothers & 23 & 58 & 5650 & 181 & 220 & +39 \\
\hline 9 & 3 uncles, 1 brother & 13 & 51 & 6250 & 652 & 729 & +77 \\
\hline 10 & 1 brother & 18 & 55 & 5550 & 229 & 530 & +301 \\
\hline 11 & 1 brother & 19 & 54 & 5575 & 668 & 729 & +61 \\
\hline 12 & 1 brother & 16 & 78 & 6900 & 400 & 871 & +471 \\
\hline
\end{tabular}

*According to pedigree evaluation subjects 7 to 12 are possible carriers of Duchenne muscular dystrophy. Because of their significantly raised serum kinase levels they are considered to be definite carriers in this study. 


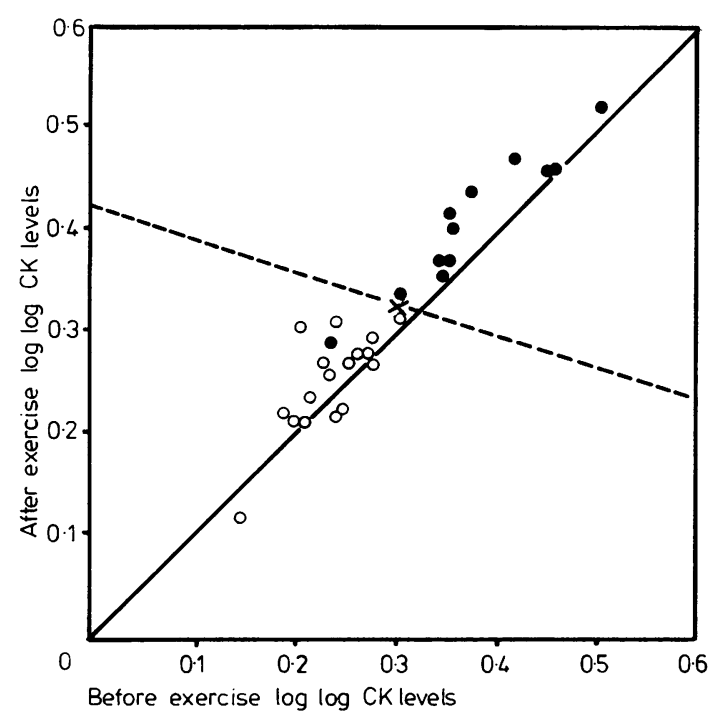

FIGURE Serum creatine kinase levels (log log transformation) in normal females $(O)$ and in carriers of Duchenne muscular dystrophy (๑) before and after exercise. - - - Discriminant boundary.

\section{Discussion}

In this study we investigated the possibility of improving the discriminating ability of serum creatine kinase by taking blood samples before and 9 hours after a measured exercise load. As previous reports $^{16-20}$ indicate, the amount of exercise is an important consideration. Emery ${ }^{23}$ reported preliminary results similar to ours, stressing the need for further study of the effects of standard exercise. Thomson ${ }^{20}$ measured creatine kinase increases after a more leisurely walk than Emery's subjects. $\mathrm{He}$ was not able to demonstrate a significant exercise effect. Hughes et $a l^{24}$ found no significant difference in bicycle exercise effects in carriers compared with controls. However, these subjects exercised somewhat less than ours, and the creatine kinase determinations were not made between 4 and 20 hours after exercise when the maximum exercise effects. would be expected. In the study of Nuttal and Jones, ${ }^{19}$ normal untrained female subjects displayed increased creatine kinase levels 8 to 16 hours after strenuous weight lifting. The exercise load given to the subjects in our study was probably between the latter two in difficulty. Although two of our control subjects had large increases in their creatine kinase after exercise, the results did not exceed the normal range ( 15 to 135 IU) in our laboratory. The exercise load of our subjects seems to be sufficient to improve the discriminating ability of creatine kinase levels. While these preliminary data provide evidence that after exercise serum creatine kinase determinations are of greater value in identifying carriers of Duchenne muscular dystrophy than randomly obtained levels, we propose a large scale study to investigate further and substantiate our result.

We would like to thank Professor Robert Reed and Dr John Pezzullo for the biostatistical evaluation of the data. We are indebted to Ms Gail BarselBowers for arranging the subjects' schedules as well as Robin O'Reilly, JoAnn Meehan, and Cynthia Clay for their assistance in preparing the manuscript. We also would like to express our appreciation to the Rhode Island Muscular Dystrophy Association, in particular $\mathrm{Mr}$ Jack Hodys and Ms Sharon Garland for their support and cooperation.

\section{References}

1 Munsat TL, Baloh R, Pearson CM, Fowler W. Serum enzyme alterations in neuromuscular disorders. JAMA $1973 ; 226: 1536-43$.

2 Alberts MC, Samaha FJ. Serum pyruvate kinase in muscle disease and carrier status. Neurology (Minneap) $1974 ; 24: 462-4$.

3 Thompson MW, Murphy EG, McAlpine PJ. An assessment of the creatine kinase test in the detection of carriers of Duchenne muscular dystrophy. $J$ Pediatr 1967;71:82-93.

4 Afifi AK, Bergman RA, Zellweger H. A possible role for electron microscopy in detection of carriers of Duchenne type muscular dystrophy. J Neurol Neurosurg Psychiatry 1973;36:643-50.

5 Gardner-Medwin D. Studies of the carrier state in Duchenne type muscular dystrophy. Quantitative electromyography as a method of carrier detection. J Neurol Neurosurg Psychiatry 1968;31:124-34.

6 Ionasescu V, Zellweger H, Shirk P, Conway T. Identification of carriers of Duchenne muscular dystrophy by muscle protein synthesis. Neurology (Minneap) 1973;23: 497-502.

7 Roses MS, Nicholson MT, Kircher CS, Roses AD. Evaluation and detection of Duchenne and Becker muscular dystrophy carriers by manual muscle testing. Neurology (Minneap) 1977;27:20-5.

8 Emery AEH. Abnormalities of the electrocardiogram in female carriers of Duchenne muscular dystrophy. $\mathrm{Br}$ Med J 1969;2:418-20.

9 Miller SF, Roses AD, Appel SH. Scanning electron microscopy studies in muscular dystrophy. Arch Neurol 1976;33:172-4.

10 Roses AD, Roses MJ, Miller SE, Hull KL, Appel SH. Carrier detection in Duchenne muscular dystrophy. $N$ Engl J Med 1976;294:193-8.

11 Falk RS, Campion D, Guthrie D, Sparkes RS, Fox CF. Phosphorylation of the red cell membrane proteins in Duchenne muscular dystrophy. $N$ Engl J Med 1975;292: 258-9.

12 Pickard NA, Gruemer HD. Lymphocyte capping in Duchenne muscular dystrophy. $N$ Engl J Med 1978; $299: 861-8$. 
13 Bradley WG, Kelemen J. Genetic counseling in Duchenne muscular dystrophy. Muscle and Nerve 1979;2:325-8.

14 Nicholson GA, Gardner-Medwin D, Pennington RJT, Walton JN. Carrier detection in Duchenne muscular dystrophy: assessment of the effect of age on detection rate with serum creatine kinase activity. Lancet 1979 ; : 692-4.

15 Perry TB, Fraser FC. Variability of serum creatine kinase activity in normal women and carriers of the gene of Duchenne muscular dystrophy. Neurology (Minneap) $1973 ; 23: 1316-23$.

16 Ledwich JR. Changes in serum creatine phosphokinase during submaximal exercise testing. Can Med Assoc J 1973;109:273-7.

17 Chahine RA, Kazantzis A, Luchi RJ, Raizner AG, Gyorkey $F$. Effects of routine treadmill testing on the serum enzymes. Cardiology 1976;61:162-9.

18 Rose LI, Bousser JE, Cooper KH. Serum enzymes after marathon running. $J$ Appl Physiol 1970;29:355-7.

19 Nuttal FQ, Jones B. Creatine kinase and glutamic oxalacetic transaminase activity in serum: kinetics of change with exercise and effect of physical conditioning. $J$ Lab Clin Med 1968;71:847-54.

20 Thomson WHS, Sweetin JC, Hamilton IJD. ATP and muscle enzyme efflux after physical exertion. Clin Chim Acta 1975;59:241-5.

21 Rosalki SB. An improved procedure for serum creatine phosphokinase determination. J Lab Clin Med 1967;69: 696-705.

${ }^{22}$ Szasz G, Gruber W, Bernt E. Creatine kinase in serum. 1. Determination of optimum reaction conditions. Clin Chem 1976;22:650-62.

23 Emery AEH. The use of serum creatine kinase for detecting carriers of Duchenne muscular dystrophy. In: Exploratory concepts in muscular dystrophy and related disorders. International Congress Series No 147. Amsterdam: Excerpta Medica, 1967.

24 Hughes RC, Park DC, Parsons ME, O'Brien MD. Serum creatine kinase studies in the detection of carriers of Duchenne dystrophy. J Neurol Neurosurg Psychiatry $1971 ; 34: 527-30$.

Requests for reprints to Dr S M Pueschel, Child Development Center, Rhode Island Hospital, 593 Eddy Street, Providence, Rhode Island 02902, USA. 